\title{
A busca pela efetivação de direitos fundamentais por meio da prestação de assistência jurídica integral e gratuita por municípios
}

\author{
The search for the effectiveness of fundamental \\ rights through the provision of integral and free \\ legal assistance by municipalities
}

Ana Carolina Couto Matheus Universidade Federal do Acre, UFAC, Rio Branco, AC, Brasil

Resumo Esta pesquisa propõe-se a examinar a possibilidade de prestação de assistência jurídica integral e gratuita pelos municípios no ordenamento jurídico brasileiro. E o objetivo geral é analisar os dispositivos constitucionais e infraconstitucionais que envolvem a questão, notadamente os que garantem ao cidadão o acesso à justiça. Para tanto, representam finalidades específicas deste trabalho em testilha: enfatizar o dever do município em concretizar os direitos fundamentais; destacar entraves da assistência jurídica brasileira que impedem prestar o serviço; demonstrar que a interpretação que mais se coaduna à Constituição é a que possibilita ao ente municipal prestar o serviço, garantindo o acesso dos munícipes à justiça. $\mathrm{O}$ método de abordagem norteador do presente estudo será o dedutivo. Considerando que o município é ente federativo, sendo sua responsabilidade, com os outros entes, concretizar os direitos fundamentais, logo a ele também foi dada competência para prestar assistência jurídica integral e gratuita àqueles que dela necessitarem. 
Será utilizada a fonte de pesquisa bibliográfica, as técnicas do referente, da categoria, do fichamento e do conceito operacional.

Palavras-chave: AcEsso À JUSTIÇA. AssistênCIA JURÍDICA. DiREITOS FUNDAMENTAis. MunicíPIO. COMPETÊNCIA.

Abstract The objective of the research is to examine the possibility of providing full and free legal assistance by the Municipalities in the Brazilian legal system. The general purpose of the research is to analyze the constitutional and infraconstitutional devices that involve the issue, especially those that guarantee the citizen access to justice. To do so, they represent specific objectives of the research in tessellation: to emphasize the duty of the Municipality to realize fundamental rights; highlight obstacles to Brazilian legal assistance that prevent service delivery; demonstrate that the interpretation that most closely matches the Constitution is the one that enables the municipal entity to provide the service, guaranteeing the access of the citizens to justice. The guiding method of the present study will be the deductive method. Considering that the Municipality is a federative entity, and its responsibility, together with the other entities, is to fulfill the fundamental rights, so it has also been given the authority to provide full and free legal assistance to those who need it. It will be used the bibliographic research source, the techniques of the referent, the category, the filing and the operational concept.

Key-words: Access to Justice. Legal assistance. Fundamental Rights. County. Competence.

\section{INTRODUÇÃO}

O propósito do presente trabalho é analisar, de forma crítica, os argumentos a favor e contra a prestação de assistência jurídica gratuita por entes municipais, à luz do princípio da máxima efetividade e do direito de acesso à justiça, assumindo-se o posicionamento mais harmônico e condizente com a atual ordem constitucional. 
A escolha do tema justifica-se em razão do princípio da máxima efetividade dos direitos fundamentais, condizente com as diretrizes estabelecidas pela Constituição da República de 1988, principalmente no que tange às normas que dispõem sobre o acesso à justiça.

O homem, como ser social, encontra-se em constantes conflitos e, na maioria das vezes, é necessária a intervenção de uma força maior e imparcial para a solução de tais desavenças, ou seja, a atuação do Estado na figura do Poder Judiciário. Entretanto, nem todas as pessoas possuem capacidade econômica e saber jurídico suficiente para intentar perante a Justiça, com fins de alcançarem seus objetivos. No cerne dessa questão, surgiu a assistência jurídica gratuita, em um primeiro momento, vinculada ao aspecto judiciário, visando a amparar hipossuficientes e auxiliá-los na busca de uma solução efetiva para os seus conflitos.

O inciso LXXIV, do artigo $5^{\circ}$., da Constituição da República Federativa Brasileira de 1988 (CRFB/88), prescreve que o Estado prestará assistência jurídica integral e gratuita aos que comprovarem insuficiência de recursos, consagrando o caráter de garantia constitucional ao que fora ali previsto. Conforme o disposto no artigo 134, da CRFB/88, a Defensoria Pública brasileira é responsável pela prestação da assistência jurídica. Porém, a Carta Magna não estabeleceu competência aos municípios para a instituição da Defensoria Pública.

Entre as inúmeras questões envolvendo a prestação da assistência jurídica no Brasil, o marco de referência objeto de estudo da pesquisa em epígrafe privilegia a temática da competência do ente municipal para a prestação daquele serviço, assunto que, nos últimos anos, vem tomando assento em discussões doutrinárias e jurisprudenciais, tendo em vista os diversos preceitos constitucionais que envolvem a matéria.

Nesse contexto, urge aprofundar os debates a respeito desse importante assunto em tela, com o objetivo principal de analisar dispositivos constitucionais e infraconstitucionais, notadamente os que garantem ao cidadão o acesso à justiça, no sentido de estudar a possibilidade de os municípios brasileiros instituírem serviços de assistência jurídica integral e gratuita, de acordo com as regras de 
competência legislativa, fixadas no texto constitucional, bem como, com os direitos fundamentais da pessoa humana.

Representam objetivos específicos deste trabalho: enfatizar o dever do município em concretizar direitos fundamentais; destacar entraves da assistência jurídica brasileira que impedem prestar o serviço; demonstrar que a interpretação que mais se coaduna à Constituição é a que possibilita ao ente municipal prestar o serviço, garantindo o acesso dos munícipes à justiça.

As questões centrais desta pesquisa são: Qual a diferença entre justiça gratuita, assistência judiciária e assistência jurídica? É possível a prestação de assistência jurídica integral e gratuita pelos municípios? O que se deve entender por acesso à justiça e a perspectiva da máxima efetividade dos direitos fundamentais? Quais os principais obstáculos que dificultam a prestação integral do direito em comento? Quais os aportes teóricos e dispositivos constitucionais que versam sobre competência legislativa e direitos fundamentais?

Para tanto, esta pesquisa foi organizada em três partes. A primeira parte aborda a evolução do serviço de assistência jurídica integral e gratuita mundial e no Brasil, seu contexto histórico, a amplitude de sua expressão, bem como, a diferença básica entre justiça gratuita, assistência judiciária e assistência jurídica. A segunda parte do trabalho versa sobre o direito de acesso à justiça, tratado especialmente sob a ótica das ondas renovatórias constatadas por Cappelletti e Garth, a interpretação dos preceitos que cuidam do tema sob a perspectiva da máxima efetividade dos direitos fundamentais, e os principais obstáculos que dificultam a prestação integral do direito em comento.

A terceira e última parte do trabalho estuda a possibilidade de prestação de assistência jurídica integral e gratuita pelos municípios, a partir da análise dos dispositivos constitucionais que versam sobre competência legislativa, bem como, daqueles que envolvem direitos fundamentais.

Em relação às opções metodológicas e recortes epistemológicos, fonte bibliográfica, as técnicas do referente, da categoria, do conceito operacional e do fichamento, trata-se de um trabalho eminentemente bi- 
bliográfico, com fulcro em estudos explanatórios, que serão utilizados para investigar alguns temas com base em novas perspectivas e ampliar os estudos já existentes.

A pesquisa emprega o método de abordagem dedutivo, que utiliza um raciocínio de uma premissa maior para obter conclusões de aspectos mais individualizados. O município, tendo sido elevado à categoria de ente federativo, possui a responsabilidade de concretizar os direitos fundamentais, portanto, a ele também foi dada competência para prestar assistência jurídica integral e gratuita àqueles que dela necessitarem.

\section{ConsideraÇões relativas À ASSISTÊnCIA JURídicA GRATUITA}

Para um estudo aprofundado acerca do instituto da assistência jurídica, é necessário tecer algumas considerações relativas ao surgimento da assistência jurídica no contexto mundial, eis que diversas características que o referido serviço possuía no passado ainda persistem até os dias atuais, bem como a apuração de seus primeiros aspectos pode ser utilizada para dirimir os obstáculos que a maculam atualmente.

Entretanto, a busca pelas origens no passado, o mais remoto possível, incorre na prática de uso da historiografia tradicional/rasa criticada, por exemplo, Baitz (2006, p. 35-55). Considerando que o objetivo desta pesquisa é a discussão sobre a atribuição municipal para atuação na assistência jurídica, prescinde dessa busca a instituição da "assistência jurídica gratuita" na antiguidade clássica.

Após a Revolução Francesa de 1789, o Decreto da Constituinte, de 16 de julho de 1790, permitiu que qualquer cidadão realizasse sua defesa em processos judiciais, por escrito ou oralmente.

Entretanto, verificou-se que a mera positivação do direito de acesso à justiça não era o suficiente para alcançar os anseios de igualdade substancial, surgindo a necessidade de criação de instituições especializadas na concessão desse serviço, tendo em vista que os advogados particulares que atuavam na defesa dos pobres já se encontravam muito atarefados para a prestação assistencial de maneira integral. 
Nas décadas de 70 e 80 do século passado, acompanhando a necessidade de especialização da assistência jurídica gratuita, iniciou-se uma série de movimentos mundiais a respeito da questão, nos quais a temática atingia seu apogeu com o Movimento Mundial de Acesso à Justiça e seu caráter tridimensional.

\begin{abstract}
Uma primeira dimensão reflete o problema, necessidade ou exigência social que induz à criação de um instituto jurídico; a segunda dimensão reflete a resposta ou solução jurídica, por sinal uma resposta que, além das normas, inclui as instituições e processos destinados a tratar daquela necessidade; enfim uma terceira dimensão encara os resultados, ou o impacto, dessa resposta jurídica sobre a necessidade, problema ou exigência social. O papel da ciência jurídica, aliás, o papel dos operadores do direito em geral, torna-se assim mais complexo, porém, igualmente muito mais fascinante e realístico (MEDEIROS, 2013, p. 51).
\end{abstract}

Em 1968, o advogado norte-americano Peter Messitte, imbuído do espírito revolucionário que os movimentos surgidos lhe propiciam, destacou a exemplaridade e o pioneirismo do modelo brasileiro em comparação com outros modelos vigentes no mundo, especialmente o vigente nos Estados Unidos, publicando estudo que destacou a admirável história da assistência judiciária no Brasil. "Basta comparar a lei brasileira sobre assistência judiciária com a lei norte-americana sobre o assunto para ver como a lei brasileira é adiantada" (CAPPELLETTI, 1998, p. 97).

Proliferaram estudos para analisar o fenômeno que tomara proporções internacionais. Em 1970, o "Projeto Florença", coordenado por Mauro Cappelletti, serviu como parâmetro para outros estudos até os dias atuais.

O Brasil se encontra ainda buscando um modelo ideal de efetivação da assistência jurídica gratuita, sobretudo quando a população hipossuficiente cresce cada vez mais e as instituições encarregadas sofrem as consequências derivadas de tal crescimento. 
Foi com o Decreto Federal n. 2.457, de 8 de fevereiro de 1897, que a assistência jurídica recebeu tratamento próprio e autônomo por parte do ordenamento jurídico brasileiro, uma vez que organizou a assistência judiciária, definindo, ainda, o conceito de pobre como toda pessoa que, tendo direitos a fazer valer, em juízo, estiver impossibilitada de pagar ou adiantar as custas e despesas do processo sem privar-se de recursos pecuniários indispensáveis para as necessidades ordinárias da própria manutenção da família.

O Decreto n. 19.408, de 18 de novembro de 1930, criou a Ordem dos Advogados Brasileiros, e por meio de seu regulamento, o patrocínio gratuito de causas por advogados deixou de ser uma recomendação para ser um dever do advogado, sob pena de multa. Quanto ao caráter de garantia individual, a assistência jurídica foi prevista constitucionalmente no artigo 113, § 32, da Carta de 1934, que permitiu à legislação supletiva dos Estados no tocante à assistência judiciária.

A Constituição de 1937 nada previu acerca da matéria, posteriormente excluída pela Constituição do Estado Novo, "em que pese a omissão constitucional no período da Ditadura Vargas, a assistência jurídica foi mantida como norma infraconstitucional no Código de Processo Civil de 1939, no Código de Processo Penal de 1941, e na Consolidação das Leis do Trabalho, em 1943" (ALVES, 2006, p. 244).

Em 1946, a norma retornou ao seu status constitucional, no $\S 35^{\circ}$. do artigo 141 da Constituição de 1946, voltando a reconhecer que os carentes necessitavam de uma proteção jurídica independente e gratuita.

Em 1950, a Lei n. 1.060, ainda em vigor, estabeleceu normas para a concessão de assistência judiciária aos necessitados, dispôs sobre o procedimento de acesso a esse serviço e às isenções a ele aplicáveis, no artigo $2^{\circ}$. fixou o conceito de "necessitado" como "todo aquele cuja situação econômica não lhe permita pagar as custas do processo e os honorários de advogado, sem prejuízo do 
sustento próprio e da família". Para Marcacini (2001, p. 95), foi a lei que melhor regulou o benefício da assistência gratuita até hoje.

O artigo 150, § $32^{\circ}$., da Constituição de 1967, tratou do tema ao afirmar que será concedida assistência judiciária aos necessitados.

$\mathrm{O}$ inciso LXXIV, do artigo $5^{\circ}$. da $\mathrm{CRFB} / 88$, tratou do tema ao dispor que "o Estado prestará assistência jurídica integral e gratuita aos que comprovarem insuficiência de recursos". Não bastava tratar da assistência judiciária como direito e garantia individual e coletiva, mas, sim, necessário também que se reconhecessem o caráter de essencialidade à justiça e a estrutura de instituição pública, esclarecendo a quem competia fornecê-la.

Dessa forma, o artigo 134 dispôs que "a Defensoria Pública é instituição essencial à função jurisdicional do Estado, incumbindo-lhe a orientação jurídica e a defesa, em todos os graus, dos necessitados, na forma do art. $5^{\circ}$., LXXIV'.

A CRFB/88, além de se ocupar extremamente com questões sociais, diferenciou-se das demais Cartas por ser a primeira a instituir a Defensoria Pública como órgão integrante do Poder Público, ao lado do Ministério Público e daAdvocacia, incumbindo a ela a prestação de assistência jurídica integral e gratuita aos hipossuficientes, elencada entre os direitos fundamentais, dando-lhes o caráter de instituição essencial à função jurisdicional.

Em 1994, a Lei Complementar n. 80 organizou a Defensoria Pública da União e do Distrito Federal, além de prescrever normas gerais para a sua organização nos Estados. Após a publicação da mencionada lei, vários Estados começaram a dispor sobre a Defensoria Pública.

Em 2004, a Emenda Constitucional n. 45 trouxe uma importante inovação, fortalecedora da instituição, inserindo no $\S 2^{\circ}$. do artigo 134 , que concedeu às Defensorias Públicas Estaduais autonomia funcional, administrativa e financeira, renumerando o antigo parágrafo único para $\S 1^{\circ}$., dispondo que "às Defensorias Públicas Estaduais são asseguradas autonomia funcional e administrativa e a iniciativa de sua proposta 
orçamentária dentro dos limites estabelecidos na lei de diretrizes orçamentárias e subordinação ao disposto no artigo 99, $\S 2^{\circ}$ ".

“Avanço inigualável e inédito no sistema constitucional brasileiro, e sem paralelo no direito comparado, a Democracia Brasileira atinge o que talvez seja o ápice de amadurecimento e expansão, com a concessão às Defensorias Públicas Estaduais" (CUNHA JR., 2013, p. 1.149).

Em 2013, foi promulgada a Emenda Constitucional n. 74, que estendeu as autonomias administrativas, funcional e iniciativa de proposta orçamentária à Defensoria Pública da União e do Distrito Federal.

A concessão de autonomia às Defensorias Públicas conferiu aumento de credibilidade do órgão perante os cidadãos, que passaram a possuir maior confiança em buscar orientação em uma instituição autônoma, não subordinada ao Poder Público e livre de pressões políticas. A assistência jurídica ainda enfrenta muitos entraves à sua efetivação, nem sempre lhe é dado o real significado que possui, uma vez que é tida como sinônimo de outros institutos também de cunho assistencial.

É necessário distinguir: justiça gratuita, assistência judiciária e assistência jurídica. Justiça gratuita consiste na dispensa de antecipação das despesas do processo, bem como, na ausência de exigibilidade das verbas derivadas de uma possível sucumbência. Tal isenção de pagamento mais se coaduna com uma imunidade e se mostra muito mais restrita do que a assistência judiciária. Quanto à extensão da justiça gratuita, o artigo $3^{\circ}$. da Lei n. 1.060/1950, estatui um rol não taxativo das isenções abrangidas pelo deferimento do instituto.

Assistência judiciária envolve o patrocínio gratuito da causa por advogado, é "um serviço público organizado, consistente na defesa em juízo do assistido, que deve ser oferecido pelo Estado, mas que pode ser desempenhado por entidades não-estatais, conveniadas ou não com o Poder Público" (MARCACINI, 2001, p. 31).

A parte gozará dos benefícios da assistência judiciária mediante simples afirmação, na própria petição inicial, de que não está em condições de pagar as custas do processo e os honorários de advogado, sem prejuízo próprio ou de sua família, nos termos do disposto na Lei n. $1.060 / 1950$. 
A diferença básica entre justiça gratuita e assistência judiciária é que, enquanto a primeira é obtida perante órgão jurisdicional que promete a prestação jurisdicional, a segunda é disciplinada por normas processuais de organização judiciária. O benefício da justiça gratuita é mais restrito do que a assistência judiciária, uma vez que compreende apenas a gratuidade das custas judiciais e dos honorários sucumbenciais derivados da prestação jurisdicional.

Quanto ao termo "assistência jurídica gratuita", engloba tanto a assistência judiciária quanto a extrajudicial, sendo muito mais abrangente. Nesse sentido, a assistência jurídica também envolve serviços jurídicos não relacionados ao processo em si, no tocante a orientações individuais, esclarecimentos de dúvidas e outras atividades sem pertinência ao âmbito processual.

Abrange a orientação e a consultoria jurídicas, inclusive de caráter preventivo, e orientações extrajudiciais, quando necessário, também garante à população a possibilidade de acesso aos meios alternativos de solução de conflitos, mais céleres e eficazes frente à morosidade do Poder Judiciário.

Assistência jurídica consiste na instauração e movimentação de processos administrativos, perante quaisquer órgãos públicos, em todos os níveis, atos de quaisquer naturezas jurídicas, praticados extrajudicialmente, bem como, a prestação de serviços de consultoria, de informação e aconselhamento em assuntos jurídicos, tanto para indivíduos como para a coletividade.

Quanto ao significado e abrangência do serviço e direito de assistência jurídica integral e gratuita, revela-se como mais uma esfera competente para defender, individual e coletivamente, em sede judicial e extrajudicial, os direitos e garantias dos quais a parcela da população pobre se encontra alijada, exigindo do Estado a atuação positiva na efetivação dos direitos fundamentais sonegados.

Segundo Krohling (2009, p. 158), os vários passos da cidadania ativa estão na consciência política, no exercício dos seus direitos, na luta pela conquista dos direitos que lhe são negados no dia a dia. $\mathrm{O}$ acesso à justiça pressupõe o conhecimento, por parte do cidadão, 
de seus direitos. "Sem a existência de instituições que possam ser consultadas pela população, sempre que houver dúvidas jurídicas sobre determinadas situações de fato, a possibilidade de plena efetividade do direito se torna reduzido" (MEDEIROS, 2013, p. 72).

Apesar de ser tratada como um serviço, a assistência jurídica gratuita deve ser vista, indiscutivelmente, como um direito fundamental e, por consequência, deve estar imbuída de toda a representatividade e importância inerente a tal categoria, sobretudo quando analisado no contexto da formação do Estado de Direito, uma vez que, além da íntima relação entre os direitos fundamentais, constituem elementos nucleares da vigente Constituição.

A população hipossuficiente não é mera destinatária, mas sim titular do referido direito. Dessa forma, o serviço de assistência jurídica gratuita e integral visa à efetivação do acesso à justiça, consagrado constitucionalmente, e que busca, precipuamente, a isonomia substancial, cujo caráter fundamental será destacado no capítulo que se segue.

\section{ACESSO À JUSTIÇA E A EFETIVIDADE DOS DIREITOS FUNDA- MENTAIS}

$\mathrm{O}$ direito de acesso à justiça pode ser entendido tanto em sentido estrito, o de acesso ao Judiciário, quanto em sentido amplo, o de acesso ao Direito.

Para Mattos (2007, p. 140), o acesso à justiça viabiliza o acesso a uma ordem jurídica justa, que abrange o direito à informação, o direito à adequação entre a ordem jurídica e a realidade socioeconômica do país, o direito ao acesso a uma justiça adequadamente organizada e o direito à preordenação dos instrumentos processuais capazes de promover a objetiva tutela dos direitos e o direito à remoção dos obstáculos que se anteponham ao acesso efetivo a uma justiça.

Acesso à justiça é garantia constitucional inserida no rol de direitos e garantias fundamentais. A inafastabilidade do acesso à tutela inte- 
gral e gratuita $\left(\mathrm{CRFB} / 88\right.$, artigo $5^{\circ}$., inciso XXXV) e o direito à assistência jurídica integral e gratuita (CRFB/88, artigo $5^{\circ}$., inciso LXXIV).

Cabe ao Estado, no exercício da atividade legislativa, e ao Judiciário, no exercício da atividade jurisdicional, propiciar meios para que esse direito seja assegurado, em todos os momentos, e não somente em uma ou outra fase processual. Estar mais voltado a princípios e não somente a normas, é condição fundamental de eficiência e validade de um sistema jurídico que vise a garantir direitos.

Acesso à justiça, para Cappelletti e Garth (1988, p. 8-11), significa o sistema pelo qual as pessoas podem reivindicar seus direitos e/ou resolver seus litígios sob os auspícios do Estado.

O sistema deve ser igualmente acessível a todos e deve produzir resultados que sejam individual e socialmente justos. Trata-se do requisito mais básico dos direitos humanos, de um sistema jurídico moderno e igualitário, que pretenda garantir e não apenas proclamar os direitos de todos.

Deve-se atribuir o caráter substancial para o acesso à justiça, assegurando-se a todos aqueles titulares de direitos que possam obter a verdadeira e efetiva tutela jurídica para o seu exercício. Os incisos I e III da CRFB/88 preveem no rol dos objetivos da República Federativa do Brasil a construção de uma sociedade justa, a erradicação da pobreza e a redução das desigualdades sociais e regionais.

É impossível separar a consecução de uma justiça social e promoção da igualdade sem a utilização de instrumentos hábeis para a sua postulação e promoção. Acesso à justiça é um dos meios mais relevantes para a realização dos objetivos republicanos constitucionalmente expostos.

$\mathrm{O}$ acesso à justiça possui caráter de direito fundamental, previsto no inciso XXV do artigo $5^{\circ}$. da $\mathrm{CRFB} / 88$, na medida em que a lei não excluirá da apreciação do Poder Judiciário lesão ou ameaça a direito. $\mathrm{O}$ inciso LXXIV, do artigo $5^{\circ}$. da CRFB/88, se refere à assistência jurídica integral e gratuita.

$\mathrm{O}$ acesso à justiça, na forma que foi contemplado na $\mathrm{CRFB} / 88$, deve possibilitar ao necessitado a superação de todos os obstáculos ao 
exercício pleno desse direito, como severas crises do Poder Judiciário, tornando custoso ao Estado efetivar o almejado direito, o descrédito da sociedade, o sentimento de insegurança jurídica, que têm forçado o Judiciário a adotar práticas alternativas para a solução de conflitos e desenham um novo enfoque que deve ser dado à questão do acesso à justiça. $\mathrm{O}$ direito à assistência jurídica e ao acesso à justiça abrange a educação em direitos, e não a mera postulação destes no âmbito processual.

$\mathrm{Na}$ busca do real sentido do direito de acesso à justiça, Cappelletti e Garth (1988, p. 12-13) reconhecem três grandes fases de desenvolvimento do movimento em questão, que orientam o estudo profundo dos obstáculos para a total efetividade do acesso à justiça e possíveis soluções visando à concretização do pleno exercício do direito em questão.

A primeira onda renovatória se preocupa em proporcionar assistência judiciária para os pobres. Na maior parte das modernas sociedades, "o auxílio de um advogado é essencial, senão indispensável, para decifrar leis cada vez mais complexas e procedimentos misteriosos, necessários para ajuizar uma causa ou até mesmo para a simples ciência da titularidade de um direito fundamental" (CAPPELLETTI; GARTH, 1988, p. 32).

A segunda onda renovatória está focada na busca da tutela de direitos coletivos. Inovou ao concentrar-se em torno da temática dos direitos difusos, rompendo o individualismo tradicional. Objetivou-se criar uma nova concepção no tocante ao tratamento das demandas, que passaram a receber uma visão com caráter mais coletivo e social dos Poderes Públicos.

“A proteção dos interesses coletivos e difusos é essencial para a adequada garantia de acesso à ordem jurídica justa numa época como a dos dias atuais, quando surgem novos direitos, sem caráter patrimonial, os chamados 'novos direitos"' (CÂMARA, 2010, p. 40), como a preservação do meio ambiente, do patrimônio cultural, histórico e artístico, a garantia da moralidade administrativa.

Para Cappelletti e Garth (1988, p. 59), os principais métodos para a representação dos interesses difusos surgidos nessa onda renovatória 
consistiam em ações governamentais, que se referiam a instituições governamentais que deveriam proteger o interesse público.

A primeira e a segunda ondas foram indispensáveis na consecução do real sentido do acesso à justiça. A terceira onda renovatória deu um novo enfoque do acesso à justiça, surgiu da necessidade de buscar novas soluções aos obstáculos.

No tocante à terceira onda, para Medeiros (2013, p. 41), ocorre a refundação de instituições e procedimentos já existentes, bem como, a criação de novas instituições e funções, dando ênfase à prevenção de litígios e a uma solução mais célere e simplificada das celeumas. Inovou ao abandonar os laços únicos que detinha com o Poder Judiciário, visando a criar o pensamento no sentido de que o acesso à justiça não se esgota no Judiciário, representa o acesso à ordem jurídica justa.

$\mathrm{O}$ acesso à justiça, considerado uma norma princípio fundamental, estimula a atuação sincronizada com outros mecanismos estruturais e organizados da sociedade, numa ação mais direta no local dos fatos, buscando resolver situações que não deveriam jamais chegar ao Poder Judiciário, em face de sua simples resolução que, na maioria das vezes, é vista como algo muito complexo pelo desconhecimento de direitos fundamentais.

No tocante à natureza jurídica, segundo o disposto no $\S 1^{\circ}$. do artigo $5^{\circ}$. da CRFB/88, as normas definidoras de direitos fundamentais têm aplicação imediata. Nesse sentido, Silva (2011, p. 180) explica que a eficácia e aplicabilidade das normas que contêm os direitos fundamentais dependem muito de seu enunciado. As normas que consubstanciam os direitos fundamentais democráticos e individuais são de eficácia e aplicabilidade imediata.

Moraes (2007, p. 27) discorda, ao afirmar que a eficácia e aplicabilidade dessas normas dependem muito de seu próprio enunciado, uma vez que a CRFB/88 faz depender de legislação ulterior a aplicabilidade de algumas normas definidoras de direitos sociais, que também se enquadram no rol daqueles tidos por fundamentais.

Referidas normas têm eficácia plena, não sendo dependentes de qualquer interposição do legislador para lograrem a efetividade ou efi- 
cácia social. Cunha Jr. (2013, p. 874) defende a aplicação imediata de todas as normas definidoras de direitos e garantias fundamentais, independentemente do seu grau de eficácia, cuja variação apresentará algumas dificuldades na efetivação dos direitos ali versados.

Conforme Silva (2011, p. 72), as normas constitucionais definidoras de direitos fundamentais podem ter eficácia plena, contida ou limitada, podem produzir todos os seus efeitos imediatamente, desde sua entrada em vigor, ou não, nos casos em que há necessidade de complementação legislativa.

Como seria possível atender à determinação contida no artigo $5^{\circ}$, $\S 1^{\circ}$., da $\mathrm{CRFB} / 88$, se nem todas essas normas possuem eficácia plena? Silva (2011, p. 180) explica que a aplicação imediata das normas definidoras de direitos fundamentais significa que elas são aplicáveis até onde possam, até onde as instituições ofereçam condições para o seu atendimento.

O Poder Judiciário, sendo invocado a propósito de uma situação concreta nelas garantida, não pode deixar de aplicá-las, conferindo ao interessado o direito reclamado, segundo as instituições existentes. Para Marinoni, Mitidiero e Sarlet (2012, p. 315), a ausência eventual de lei não pode servir de obstáculo absoluto à aplicação da norma de direito fundamental e da extração de efeitos úteis, vai depender de qual o direito em causa e de seus limites fáticos e jurídicos.

Sendo tais normas de aplicabilidade imediata, constata-se a manifestação do princípio da máxima efetividade dos direitos fundamentais, eis que deve ser concedida máxima capacidade de regulamentação às normas fundamentais, a fim de otimizarem sua materialização do mundo real acompanhado das demais normas.

$\mathrm{O}$ acesso à justiça abrange todas as áreas do poder, de maneira que os cidadãos possam exercer seus direitos. Garantem-se os fundamentos da democracia e da estrutura de um Estado fundado sobre suas bases.

$\mathrm{O}$ acesso à justiça deve ser compreendido como um direito fundamental, pois proporcionando-se o mínimo existencial ao cidadão, efetiva-se a dignidade da pessoa humana. A igualdade substancial está estreitamente ligada à efetividade dos direitos fundamentais. Para Ca- 
notilho (2002, p. 250), a uma norma constitucional deve ser atribuído o sentido que a maior eficácia lhe dê, constatando-se a existência do princípio interpretativo da máxima efetividade dos direitos fundamentais.

$\mathrm{O}$ artigo 134, da CRFB/88, atribuiu às Defensorias Públicas o dever precípuo de prestar a orientação jurídica e defesa, em todos os graus, dos necessitados. Referido serviço também vem sendo habitualmente prestado por diversos órgãos, mediante convênio, a título de trabalho gratuito no âmbito do estágio curricular em cursos de Direito.

Em relação aos principais obstáculos ao acesso à justiça e à assistência jurídica gratuita e integral no Brasil, a realidade se mostra distinta dos anseios almejados pela previsão legal. A maioria dos obstáculos que impedem o efetivo funcionamento do modelo de assistência jurídica previsto na CRFB/88 tem cunho institucional, e especialmente eles consistem em problemas de caráter orçamentário, dificuldades ante o número de defensores e de pessoal e precariedades estruturais.

Sem as devidas condições de trabalho e sem a remuneração adequada aos prestadores do serviço, prejudicam os serviços jurídicos para os pobres. O número de pessoas potencialmente usuárias do serviço é muito superior à sua capacidade de atendimento, o que dificulta a integralidade da assistência jurídica, bem como, a efetividade do direito de acesso à justiça.

A carreira dos Defensores Públicos demonstra certa inferiorização em relação à Magistratura e ao Ministério Público, há uma hierarquização dos serviços públicos que não deveria existir, deixando evidente que o serviço de assistência jurídica aos pobres não é tratado de forma prioritária, em que pese a essencialidade a ele dado pela $\mathrm{CRFB} / 88$.

Somando os problemas relacionados ao aspecto cultural da própria sociedade, revela-se a influência na precariedade da efetivação desse direito. Ainda com a reconhecida indispensabilidade e a autonomia garantida pela CRFB/88, certo é que as Defensorias Públicas ainda passam por grandes dificuldades que impedem de exercer, na integralidade, suas funções institucionais, prejudicando os necessitados. 


\section{A buSCA DA EFETIVIDAdE DE DiREITOS FUNDAMENTAIS POR} MEIO DA PRESTAÇÃO DO SERVIÇO DE ASSISTÊNCIA JURÍDICA INTEGRAL E GRATUITA POR MUNICÍPIOS

O propósito do presente trabalho é analisar, de forma crítica, os argumentos a favor e contra a prestação de assistência jurídica gratuita por entes municipais. Urge fazer uma importante ressalva, no sentido de que, apesar de conter relação com a temática, esta pesquisa não analisará a repartição de recursos no modelo federativo brasileiro, em razão da necessidade de delimitar o seu objeto.

Em relação à autonomia municipal e à busca da efetivação dos direitos fundamentais, o município, a partir do artigo 29 da CRFB/88, passou a gozar do status de entidade estatal integrante da Federação. Além de autonomia política, adquiriu o poder de auto-organização, mediante lei orgânica, bem como, autonomia administrativa, normativa, financeira.

Ao município não foi dada expressamente competência para prestar a assistência jurídica integral e gratuita. Ao município deve ser estendida a obrigação contida nos incisos I e III, do artigo $3^{\circ}$. da CRFB/88, que preveem, no rol dos objetivos da República Federativa do Brasil, a construção de uma sociedade justa, a erradicação da pobreza e a redução das desigualdades sociais e regionais.

Para o cumprimento efetivo dessa obrigação, o ente municipal deve dispor de meios eficazes que tragam resultados positivos à sociedade. $\mathrm{O}$ acesso à justiça é um dos meios mais relevantes para propiciar a realização dos objetivos republicanos constitucionalmente expostos.

Para alcançar a efetiva assistência jurídica e o efetivo acesso à justiça, mudanças devem ocorrer no atual sistema vigente para incluir outras formas de assistência, incluindo a prestação do serviço pela municipalidade.

Para Mendes (2008, p. 118), as garantias do acesso à justiça devem ser mais do que formalmente previstas, devem consubstanciar a realidade, interpretadas à luz do princípio da máxima efetividade dos direitos fundamentais. 
Legisladores, intérpretes, magistrados, promotores e até membros da Defensoria Pública não assimilaram o alcance da prestação de assistência jurídica também por parte dos municípios e continuam intentando ações de declaração de inconstitucionalidade, ações civis públicas e manifestando repúdio a cada tentativa dos entes municipais de implementarem políticas com vistas a tornar concreto o direito de assistência jurídica integral e, por conseguinte, o de acesso à justiça.

Para uma maior efetividade do direito fundamental de acesso à justiça, é preciso a busca de soluções. Mediação, arbitragem, mecanismos que proporcionam maior participação popular no Poder Judiciário, ampliam a legitimação para agir na tutela coletiva, a presença de juízes leigos nos Juizados Especiais, a criação de tribunais de vizinhança e centros de justiça de bairros, a justiça restaurativa e a criação de conselhos populares de controle da administração da justiça.

Torres (2005, p. 80) cita a descentralização da Justiça como meio alternativo à consecução da efetividade do direito em questão.

A democracia tem como fundamento o respeito às leis, ao direito e ao poder constituído. Inexiste afirmação do Estado Democrático de Direito se não há um efetivo acesso à justiça.

Inexiste Estado Democrático se o cidadão não recebe orientação nem apoio suficientes no tocante aos seus direitos. Iniciativas que visem aperfeiçoar o alcance desse direito são as que mais coadunam com a finalidade do legislador constitucional.

O Sistema Nacional de Assistência Jurídica (SINAJUR) é uma proposta de modelo democrático ancorado na livre escolha pelo cidadão carente, de qual advogado, público ou privado, irá representá-lo judicialmente, ou emitir mera consulta jurídica, ficando assegurado o direito de escolha, do acesso à justiça e o princípio da confiança no advogado para o atendimento no âmbito jurídico.

Torres (2005, p. 88) defende o modelo dos Juizados Especiais Cíveis e Criminais como sistema a ser seguido por toda a Justiça. Medeiros $(2013$, p. 111) também defende a adoção de novos métodos de acesso à justiça, serviços legais inovadores prestados de forma descentralizada, em locais próximos à comunidade para os quais se destinam. 
Para Devisate (2002, p. 265), é inevitável questionar o atual modelo de acesso à justiça, permitir direito e justiça acessíveis a todos os cidadãos, instrumento mais importante para viabilizar os demais direitos existentes.

Aliada a tais medidas alternativas poderia existir também a atuação dos municípios na temática de acesso a uma ordem jurídica justa, em que pese esteja longe de ser aceita pela majoritária comunidade jurídica.

O inciso XIII, do artigo 24, da CRBF/88, estabelece a competência da União, Estados e ao Distrito Federal para legislar sobre assistência jurídica e defensoria pública. O dispositivo não faz referência expressa à criação de Defensoria Pública Municipal, tampouco à competência do ente municipal para legislar acerca dessa instituição.

Entretanto, alguns municípios editaram leis criando Defensorias Públicas em suas circunscrições, como ocorreu com o município de Itabuna, na Bahia, que editou a Lei Municipal n. 2.114/2009, cujo inciso II do artigo $9^{\circ}$. criava a Defensoria Pública Municipal, em razão da falta de estrutura nas unidades da Defensoria Pública no interior da Bahia e a pequena quantidade de defensores públicos para atender ao público, frente às inúmeras demandas dos necessitados.

Em 2012, contra tal criação, a Associação dos Defensores Públicos do Estado da Bahia propôs ação direta de inconstitucionalidade em face da referida lei municipal, sob o fundamento de que o município não possui competência para legislar sobre Defensoria Pública, de maneira que, assim, teria invadido a competência constitucional da União e dos Estados.

Em 2013, o Tribunal de Justiça da Bahia julgou procedente a ação. Igualmente o município de Xapuri, no Estado do Acre, editou a Lei n. 764/2013, que instituiu a Defensoria Pública Municipal.

A Defensoria Pública do Estado do Acre ingressou com ação civil de improbidade administrativa e o juiz competente deferiu a medida liminar pleiteada para suspender os serviços instituídos pela lei municipal, sob fundamento de que a atuação dos municípios na edição de leis sobre assistência jurídica e Defensoria Pública viola o princípio do pacto federativo, trata de matéria de competência legislativa reservada 
apenas à União, estabelecendo normas gerais, e aos Estados e ao Distrito Federal, dispondo de forma suplementar acerca do tema.

Porém, é cediço que a finalidade precípua da CRFB/88 é "implantar uma ordem jurídica justa na vida social” (DINIZ, 2005, p. 401).

A prestação de assistência jurídica integral e gratuita é garantida aos brasileiros, deve ser concretizada para atender ao máximo de cidadãos que necessitem, nos termos do princípio de interpretação da máxima efetividade dos direitos fundamentais.

É necessário criar um sistema descentralizado de assistência jurídica integral e gratuita, notadamente com a atuação dos municípios, objetivando a inclusão de milhares de pessoas que atualmente se encontram à margem desse direito.

O município pode estruturar políticas públicas para suprir deficiência da prestação de assistência jurídica gratuita pelos órgãos dos Estados e da União. Considerando o acesso à justiça como direito fundamental, o município, como ente federativo, não está obrigado a cumprir a mandamus constitucional.

O município possui competência concorrente para prestar assistência jurídica integral e gratuita aos que comprovarem insuficiência de recursos. A CRFB/88 não vedou ao município a prestação de assistência jurídica integral e gratuita, nos termos do inciso LXXIV da CRFB/88. O suposto monopólio na prestação do serviço assistencial viola o Estado Democrático de Direito.

A matéria foi tratada no Anteprojeto de Lei de Assistência Jurídica Integral e Gratuita que equiparou os entes estatais e incorporada no Programa Estadual de Direitos Humanos do Estado de São Paulo. Apesar de o município não ser obrigado, não pode ser alijado desse ofício, vez que é o núcleo político-administrativo mais próximo dos cidadãos em cujo âmbito travam as demandas do cotidiano.

Em 2013, o Grupo Nacional de Membros do Ministério Público publicou nota técnica referente ao tema assistência jurídica e defendeu a descentralização do serviço, alegando que o artigo 134 da CRFB/88 não assegurou o monopólio desse serviço às Defensorias Públicas. 
O Ministro Dias Toffoli, do Supremo Tribunal Federal, no julgamento da Ação Direta de Inconstitucionalidade n. 4.163, de São Paulo, sinalizou entendimento a favor da prestação de assistência jurídica por outros meios que não somente aqueles prestados por intermédio das instituições de Defensoria Pública.

$\mathrm{O}$ artigo $1^{\circ}$., da Lei n. 1.060/1950, menciona a possibilidade de os municípios colaborarem na prestação do serviço de assistência jurídica. Para melhoria do sistema, é de profundo interesse público que o município também seja prestador do referido serviço, sobretudo pela instituição de políticas públicas no âmbito do poder municipal relacionadas aos mecanismos alternativos de efetivação do acesso à justiça.

A efetivação de um serviço de assistência jurídica integral e gratuita pelos municípios decorre da necessidade de se garantir à população o pleno acesso à justiça em todas as suas esferas, possibilitando- lhes uma vida digna, e atendendo ao princípio da máxima efetividade dos direitos fundamentais.

\section{ConsideraÇões FinAis}

A promulgação da $\mathrm{CRFB} / 88$ representou um marco histórico para a consolidação do Estado Democrático de Direito no Brasil, notadamente quanto à elevação da dignidade da pessoa humana, a princípio fundamental do Estado, decorrendo a previsão de um vasto campo de direitos e garantias do indivíduo, entre os quais a prestação de assistência jurídica integral e gratuita àqueles que comprovarem insuficiência de recursos (CRFB/88, art. 5\%., inciso LXXIV).

Atualmente, milhares de brasileiros batem às portas das Defensorias Públicas, instituição responsável pela prestação daquele serviço, objetivando receber orientação jurídica e defesa perante o Poder Judiciário e também fora dele.

As Defensorias Públicas federais e estaduais não são capazes de atender a todas as demandas, haja vista o alarmante número de casos concretos que recebem diariamente. Os mais prejudicados são os hipossuficientes, que muitas vezes não têm suas petições atendidas, 
tampouco são orientados da maneira correta para agir de determinada forma.

Visando à melhoria do sistema, é de profundo interesse público que o ente municipal também preste o serviço de assistência jurídica. Urge ressaltar que não se está defendendo a constitucionalidade das denominadas defensorias públicas municipais, mas sim a prestação de tal serviço por outros meios, sobretudo pela instituição de políticas públicas no âmbito do poder municipal, devendo ser aplicados concretamente os diversos meios alternativos de solução do problema.

Cabe ao município, como ente da Federação e garantidor da concretização dos direitos fundamentais, aplicar políticas públicas com o fim de prestar assistência jurídica integral e gratuita aos hipossuficientes e, por conseguinte, garantir o acesso à justiça àqueles que ainda vivem à margem da sociedade.

Dessa forma, objetivou-se demonstrar com a presente pesquisa que o reconhecimento da competência do município, como ente federativo, para prestar assistência jurídica integral e gratuita aos hipossuficientes, ao lado da União, dos Estados e do Distrito Federal, potencializa o princípio da máxima efetividade dos direitos fundamentais, bem como, o direito de acesso à justiça.

Em relação à abordagem histórica da assistência jurídica integral e gratuita, foram constatadas as características desse serviço essencial nos dias atuais, bem como, os obstáculos que o impedem de ser prestado efetivamente. A afirmação de que a assistência jurídica é um serviço gratuito não é de todo correta, porque se trata de um direito fundamental da pessoa humana, constitucionalmente consagrado.

A assistência jurídica não se exaure na mera representação por advogado em juízo, porquanto é atividade que vai além, alcançando a mera informação ou orientação aos hipossuficientes, sem que seja necessário existir uma demanda judicial. Quanto ao direito de acesso à justiça, restou demonstrado que este guarda íntima relação com a assistência jurídica integral e gratuita, dela fazendo parte como se fosse um só instituto. 
Conforme o ensinamento dos ilustres juristas Mauro Cappelletti e Bryant Garth, restou evidenciado o novo enfoque do acesso à justiça, introduzido pela terceira onda renovatória do movimento mundial desse acesso, no qual se entende que tal direito se refere ao acesso a uma ordem jurídica justa, e não à mera postulação perante o Poder Judiciário. Foram analisados os argumentos favoráveis e contrários à prestação de assistência jurídica integral e gratuita pelos entes municipais.

A pesquisa resultou no entendimento de que restringir a assistência jurídica aos órgãos da Defensoria Pública consiste também em restringir o princípio constitucional do livre e integral acesso à justiça, levando-se em conta seu novo enfoque. Destacou-se que a CRFB/88 não estabeleceu qualquer monopólio da assistência jurídica, possibilitando que outros órgãos, bem como, entidades ligadas ao Poder Público, prestem aos indivíduos economicamente carentes tal serviço, assegurando-lhes o acesso à Justiça de forma irrestrita.

Assim, a autonomia municipal, consistente na capacidade de autogoverno, auto-organização, autoadministração e normatização próprias, aliadas ao princípio da máxima efetividade por meio do qual deve ser interpretada a norma que atribui ao poder público esse ofício, isto é, a CRFB/88, autorizam a implementação do serviço por parte do ente federativo em questão.

Considerando todas as ponderações feitas no desenvolvimento da pesquisa, não obstante o artigo $134, \S 1^{\circ}$., da $\mathrm{CRFB} / 88$, tenha deixado de mencionar o município como competente para legislar e desempenhar a função da assistência jurídica integral e gratuita, bem como, o princípio da dignidade da pessoa humana consagrado na $\mathrm{CRFB} / 88$, e também o direito de acesso à justiça, que deve ter sempre sua aplicabilidade otimizada, o entendimento de que o ente municipal pode instituir o serviço de assistência jurídica integral e gratuita é o que mais se coaduna com o ordenamento jurídico brasileiro. 


\section{REFERÊNCIAS}

ACRE, Comarca da vara única de Xapuri. Ação de improbidade administrativa n. 700147-09.2013.8.01.0007. Autor: Associação dos Defensores Públicos do Estado do Acre. Réu: Márcio Pereira Miranda. Xapuri, 15 de junho de 2013. Disponível em: <http://www.anadep.org.br/wtksite/conteudo/17716/ LIMINAR_-_XAPURI.pdf>. Acesso em: 9 mai. 2017.

ALVES, Cleber Francisco. Justiça para todos. Rio de Janeiro: Lumen Juris, 2006.

BAHIA, Tribunal de Justiça do Estado. Ação direta de inconstitucionalidade n. 312384-87.2012.8.05.0000, da 2a Câmara Cível da Comarca de Itabuna. Autor: Associação dos Defensores Públicos do Estado da Bahia. Réu: Câmara Municipal de Itabuna. Itabuna, 20 de outubro de 2013. Disponível em: $<$ http:// www.esaj.tjba.jus.br/cpo/sg/search>. Acesso em: 9 mai. 2017.

BAITZ, Rafael. O saber histórico na pesquisa jurídica (as teses acadêmicas e suas introduções históricas). In: BOUCAULT, Carlos Eduardo de Abreu (Org.). História e método em Pesquisa Jurídica. São Paulo: Quartier Latin, 2006.

BRASIL. Lei Complementar n. 80, de 12 de janeiro de 1994. Organiza a Defensoria Pública da União, do Distrito Federal e dos Territórios e prescreve normas gerais para a sua organização nos Estados, e dá outras providências. Disponível em: <http://www.planalto.gov.br/ccivil_03/leis/LCP/Lcp80.htm>. Acesso em: 20 abr. 2017.

Lei n. 1.060, de 5 de fevereiro de 1950. Estabelece normas para a concessão de assistência judiciária aos necessitados. Disponível em: $<$ http:// www.planalto.gov.br/ccivil_03/leis/11060.htm>. Acesso em: 23 abr. 2017.

. Supremo Tribunal Federal. Ação direta de Inconstitucionalidade 4.163. Requerente: Procurador-Geral da República. Requerido: OAB. Relator: Min. Cezar Peluso. Brasília, 29 de fevereiro de 2012. Disponível em: <http://www. stf.jus.br/portal/processo/ver ProcessoPeca.asp?id=126466161\&tipoApp=. pdf > . Acesso em: 19 abr. 2017.

CÂMARA, Alexandre Freitas. Lições de direito processual, 20. ed. Rio de Janeiro: Lumen Juris, 2010. 
CANOTILHO, José Joaquim Gomes. Direito constitucional e teoria da constituição, 6. ed. Coimbra: Livraria Almedina, 2002.

CAPPELlETTI, Mauro; GARTH, Bryant. Acesso à justiça. Porto Alegre: Sergio Antonio Fabris, 1998.

CUNHA JR., Dirley da. Curso de direito constitucional, 7. ed. Salvador: Juspodivm, 2013.

DALLARI, Dalmo de Abreu. Apoio jurídico e integração à cidadania. Revista do Advogado. São Paulo: AASP, n. 59, 2000.

DEVISATE, Rogério dos Reis. Acesso à justiça. Rio de Janeiro: Lumen Juris, 2002 .

DINIZ, Maria Helena. Compêndio de introdução à ciência do direito, 17. ed. São Paulo: Saraiva, 2005.

FEICHAS, Roger Vieira. Da inconstitucionalidade da criação da Defensoria Pública municipal. Disponível em: <http://jus.com.br/artigos/13284/dainconstitucionalidade-da-criacao-da-defensoria-municipal/2>. Acesso em: 25 abr. 2017.

KROHLING, Aloísio. Direitos humanos fundamentais: diálogo intercultural e democracia. São Paulo: Paulus, 2009.

MARCACINI, Augusto Tavares Rosa; RODRIGUES, Walter Piva. Anteprojeto de lei de assistência jurídica integral e gratuita. Disponível em: $<$ http:// www.revistas.usp.br/rfdusp/article/view/67410>. Acesso em: 2 mai. 2017.

MARINONI, Luiz Guilherme; MITIDIERO, Daniel; SARLET, Ingo Wolfgang. Curso de direito constitucional, 2. ed. São Paulo: RT, 2012.

MATTOS, Fernando Pagani. Aspectos e os espectros ao acesso à justiça, 147s. Dissertação (Mestrado em Ciência Jurídica), Curso de Pós-Graduação stricto sensu em Ciência Jurídica, Universidade do Vale do Itajaí (UNIVALI), Itajaí, 2007.

MORAES, Alexandre de. Direito constitucional, 22. ed. São Paulo: Atlas, 2007.

MORAES, Guilherme Peña de. Instituições da defensoria pública. São Paulo: Malheiros, 1999. 
MEDEIROS, Isabela. Assistência jurídica gratuita. Rio de Janeiro: Lumen Juris, 2013.

MENDES, Gilmar Ferreira. Curso de direito constitucional, 2. ed. São Paulo: Saraiva, 2008.

PASOLD, Cesar Luiz. Metodologia da pesquisa jurídica: teoria e prática, 12. ed. São Paulo: Conceito Editorial, 2011.

SILVA, José Afonso da. Curso de direito constitucional positivo, 31. ed. São Paulo: Malheiros, 2011.

SISTEMA NACIONAL DE ASSISTÊNCIA JURÍDICA (SINAJUR). O SINAJUR. São Paulo, 2006. Disponível em: <http://www.sinajur.org>. Acesso em: 5 mai. 2017.

TORRES, Jasson Ayres. O acesso à justiça e soluções alternativas. Porto Alegre: Livraria do Advogado, 2005.

\section{SOBRE A AUTORA}

Ana Carolina Couto Matheus

Doutoranda em Ciência Jurídica pela UNIVALI - SC. Mestre em Direito Processual pela UNIPAR - PR. Especialista em Direito Tributário pela UnP - RN. Pós-graduada em Direito Constitucional pela UVB - PR. Bacharel em Direito pela TOLEDO - SP. Professora Adjunta, nível 3, do Curso de Graduação em Direito da UFAC. Advogada. Consultora jurídica. Orientadora. Conferencista. Autora de diversas obras jurídicas. Pesquisadora.

CV: http://lattes.cnpq.br/1860782485840821

E-mail: carolcoutomatheus@hotmail.com.

Submetido em: 9-8-2017

Aceito em: 8-11-2017 